\title{
Purpura fulminans with haemolytic anaemia
}

\author{
N. A. NAGI \\ M.B., CH.B., M.M.Sc. \\ A. R. A. Al-Hasso \\ M.B., CH.B., PH.D.

\begin{abstract}
Department of Paediatrics and Department of Pathology, College of Medicine, University of Mosul, Iraq
\end{abstract}

\begin{abstract}
Summary
A 10-month-old female infant with purpura fulminans is reported. The patient had clotting abnormality compatible with consumption coagulopathy. Histopathological examination revealed the presence of microthrombi. Heparin was effective in correcting the clotting defects. The infant also suffered from microangiopathic haemolytic anaemia. She died 17 days after the onset of the illness from infection in spite of antibiotic therapy.
\end{abstract}

PURPURA fulminans is a rare but catastrophic and often a fatal disease of children with a mortality rate of over $90 \%$. Death usually takes place within the first 48-72 hr. The survivors frequently suffer from a serious morbidity, and limb amputation is commonly required (Charkes, 1961; Fishbein, 1969). A preceding infection such as chickenpox, measles, scarlet fever, streptococcal pharyngitis, meningococcaemia and exanthems frequently occurs (Dunn, 1951; Chambers, Holyoke and Wilson, 1952; Bauhasin, 1964; Allen, 1966; Cram and Soley, 1968). The onset of the illness is abrupt with the appearance of ecchymotic purpuric areas, mostly in the lower extremities, with a striking symmetry. The purpuric areas progress rapidly, becoming dark in colour and end with tissue necrosis and gangrene. The trunk and upper extremities are rarely involved. Melaena, haematuria, involvement of the lung, spinal cord and sciatic nerve have been observed (Allen, 1966; Brown and Nelson, 1967; Dudgeon et al., 1971). Apart from the characteristic external manifestations of the illness, the patient may suffer from fever, chill, haemorrhagic shock and coma.

Many authors have commented upon similarities between purpura fulminans and Schwartzman phenomenon as seen in experimental animals. These similarities are based on histological and laboratory studies. Histological examination in purpura fulminans has shown microthrombi of the small blood vessels with perivascular infiltration of the involved area (Heal and Kent, 1953). The blood clotting mechanism of these patients reveals defects similar to those seen with the so-called hypercoagulable state and purpura fulminans has been included in the growing list of conditions characterized by Disseminated Intravascular Coagulation (DIC). Little (1959) has suggested the descriptive eponym, Post-infectious Intravascular Thrombosis with Gangrene. On the assumption that thrombosis and consequent consumption of clotting factors is the basic defect in purpura fulminans, heparin with its antithrombin activity has been used in management.

This communication describes a 10-month-old female infant with a typical clinical picture and characteristic laboratory findings. In addition, at onset of the illness she was found to have a profound microangiopathic haemolytic anaemia.

\section{Case report}

K.R., a 10-month-old girl, was well until 10 days before admission to Mosul Children's Hospital 0 when she developed fever and cough. She responded? initially to treatment with tetracycline but was admitted because of advancing ecchymosis of the right thigh. The past and family history were not contributory. Physical examination showed an acutely ill child with a temperature of $38^{\circ} \mathrm{C}$; pulse, $100 / \mathrm{min}$; respiration, $30 / \mathrm{min}$; blood pressure, 80 $\mathrm{mmHg}$ and weight $7 \mathrm{~kg}$. Positive findings were restricted to the right lower extremity where a large ecchymosis occupying most of the upper half of the thigh was situated on the medial side. Radial, femoral and popliteal pulses were palpable. The ecchymosis increased in size during the first $24 \mathrm{hr}$ after admission and bullae developed at the periphery. The right thigh and leg were swollen. The patient looked toxic and moribund with oozing of blood from her mouth (Fig. 1). Laboratory data are given in Table 1 . The peripheral blood film showed a large number of irregularly contracted and fragmented erythrocytes including triangular, helmet and pincered cells, an appreciable number of nucleated red cells and polychromasia (Fig. 2). These findings suggested that intravascular coagulation with a concomitant haemolytic anaemia was in progress. The patient was transfused with $150 \mathrm{ml}$ of fresh blood and a continuous intravenous drip was started containing heparin $100 \mathrm{iu} / \mathrm{kg}$ body weight 4 hourly plus penicillin and chloromycetin. Twenty- 

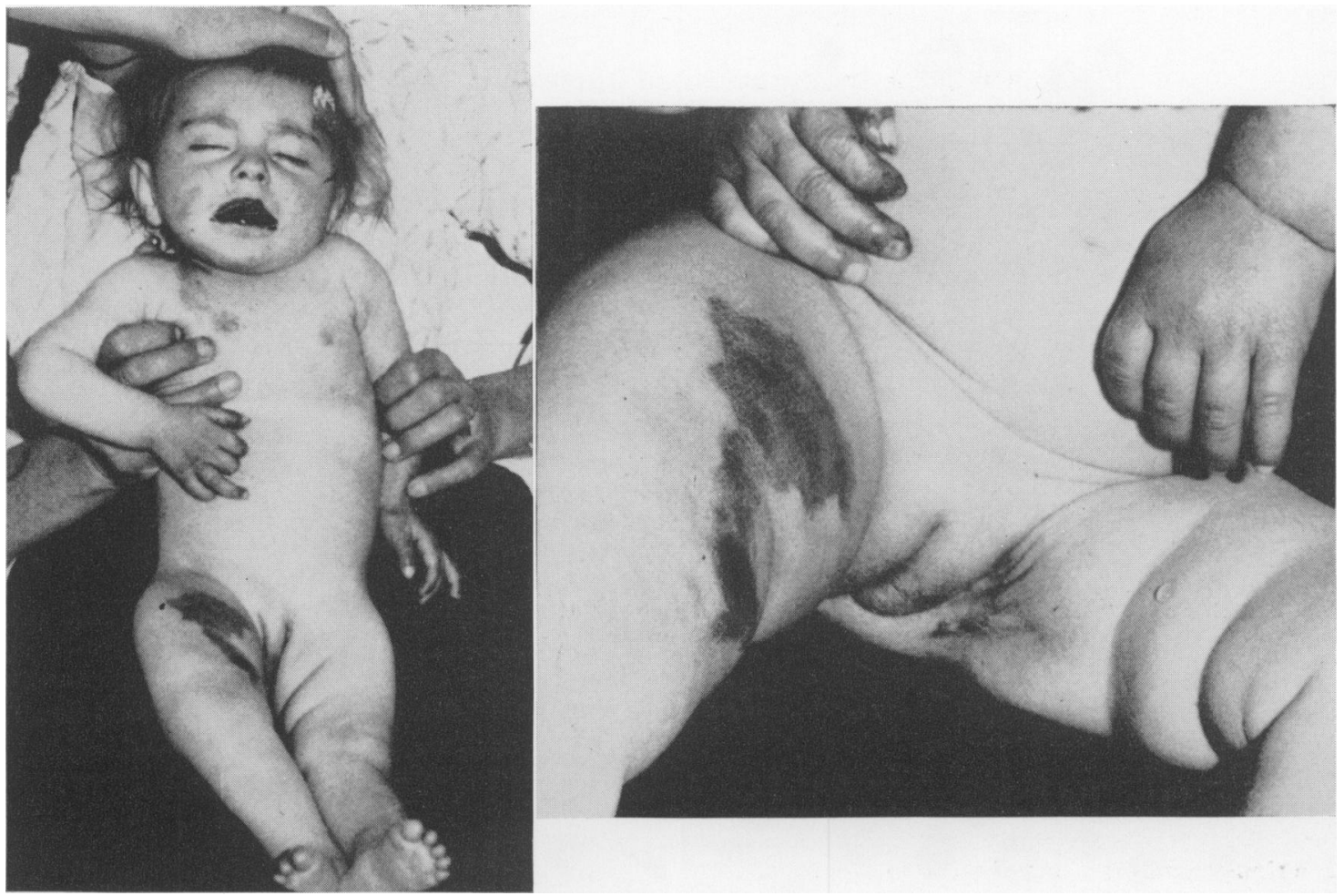

FIG. 1. Photographs of the patient on the second hospital day.

TABLE 1. Laboratory data

\begin{tabular}{|c|c|c|}
\hline & Before heparin therapy & After heparin therapy \\
\hline $\begin{array}{l}\text { Haemoglobin } \\
\text { Packed cell volume } \\
\text { Mean corpuscular haemoglobin }\end{array}$ & $\begin{array}{c}4.3 \mathrm{~g} / 100 \mathrm{ml} \\
15 \%\end{array}$ & $\begin{array}{c}14 \cdot 3 \mathrm{~g} / 100 \mathrm{ml} \\
47 \%\end{array}$ \\
\hline concentration & $29 \%$ & $30 \%$ \\
\hline Reticulocyte count & $10 \%$ & $1 \%$ \\
\hline White blood cell count & $8200 / \mathrm{mm}^{3}$ & $5000 / \mathrm{mm}^{3}$ \\
\hline Red blood cell morphology & Marked fragmentation & Occasional distortion \\
\hline Platelet count & $50,000 / \mathrm{mm}^{3}$ & $120,000 / \mathrm{mm}^{3}$ \\
\hline Bleeding time & Excessively prolonged & $6 \mathrm{~min}$ \\
\hline Clotting time & $>1 \mathrm{hr}$ & $15 \mathrm{~min}$ \\
\hline Prothrombin time & $150 \mathrm{sec}$ (control, $15 \mathrm{sec}$ ) & $17 \mathrm{sec}$ (control, $15 \mathrm{sec}$ ) \\
\hline Partial thromboplastin time & $360 \mathrm{sec}$ (control, $60 \mathrm{sec}$ ) & $106 \mathrm{sec}$ (control, $65 \mathrm{sec}$ ) \\
\hline Plasma fibrinogen & $20 \mathrm{mg} / 100 \mathrm{ml}$ & $250 \mathrm{mg} / 100 \mathrm{ml}$ \\
\hline
\end{tabular}

four hours from the onset of therapy she was less toxic with a normal temperature and the oozing of blood from the mouth had ceased. Seventy-two hours from the onset of therapy, coagulation studies, urinanalysis, blood urea, SGPT activity, serum protein electrophoresis and X-rays of the chest, right femur and leg, were normal (Table 1).

Heparin therapy was discontinued on the eighth day and $24 \mathrm{hr}$ later, surgical debridement of the lesions of the right thigh was performed. There was extensive sloughing and necrosis involving the skin, subcutaneous tissues and muscle layers. Coagulation studies before and after surgery were normal and the patient tolerated the procedure well without excessive bleeding. Histological examination of the removed tissues showed thrombosis of small blood vessels with perivascular infiltration, damage of vascular endothelium and tissue necrosis (Fig. 3). Culture from the material showed growth of Staphylococcus aureus sensitive to gentamicin which 


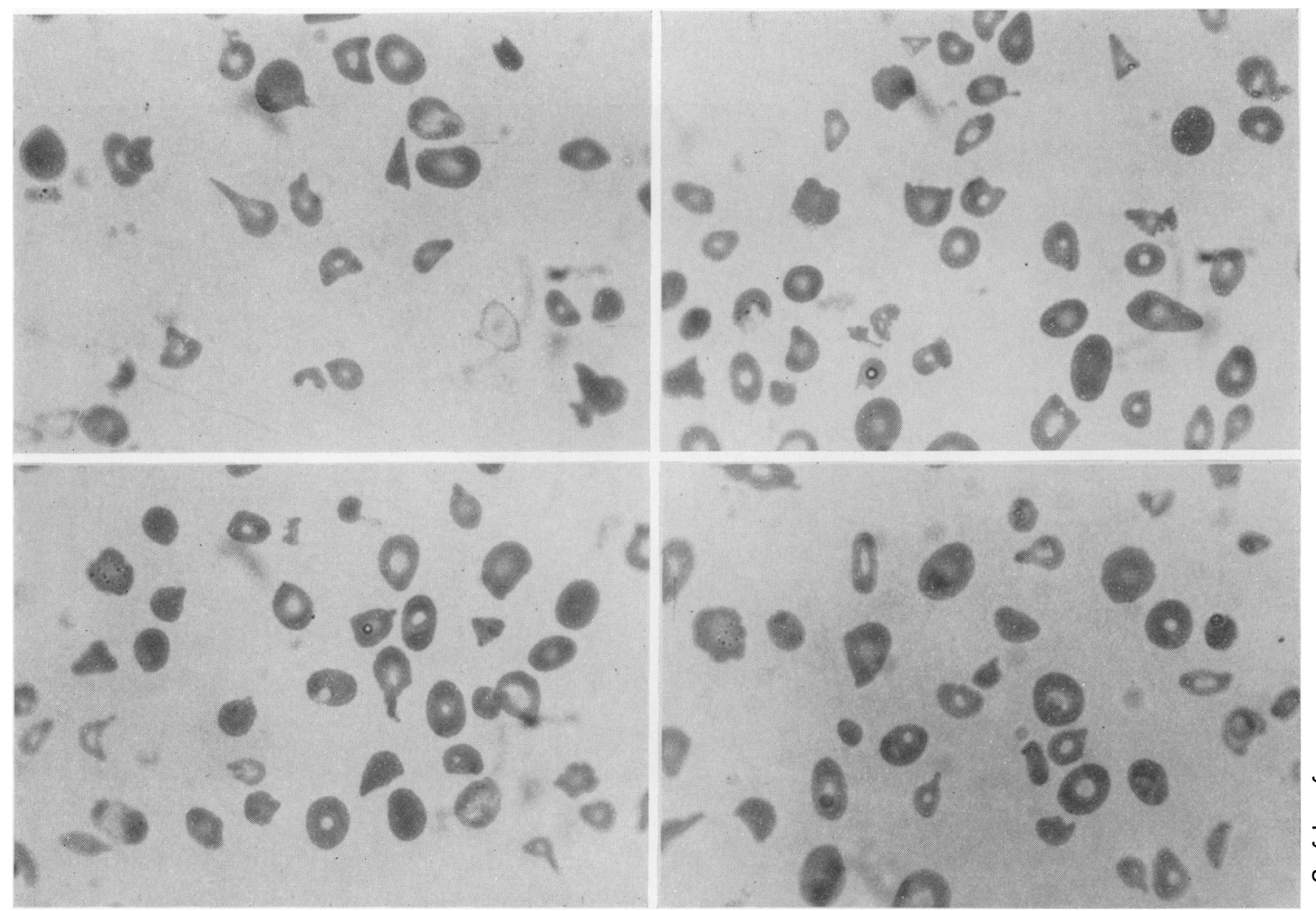

Fig. 2. Blood film of the patient before heparin therapy, showing fragmented and irregularly contracted erythrocytes (Leishman's stain $\times 630$ ). (From different fields.)

was given from the twelfth day. One week after surgery she developed fever, lethargy and anorexia. On physical examination bilateral crepitations were heard and a diagnosis of septicaemia and pneumonia was made. Penicillin and chloromycetin therapy was resumed in addition to gentamicin but there was rapid deterioration in her general condition and she died 17 days after admission. Permission for autopsy was refused.

\section{Discussion}

Our patient fulfilled Hjort, Rapaport and Jorgensen's (1964) criteria for the diagnosis of purpura fulminans. (1) It is a disease of children; (2) it is preceded by a benign infection; (3) there is bleeding into skin after a latent period following the infection with rapid progression; (4) survivors after the critical period develop extensive skin necrosis following the blood coagulation abnormality with intravascular thrombosis; (5) thrombosis can be demonstrated in biopsy material from the involved area.

The aetiology of purpura fulminans remains unclear and the significance of the preceding infection is uncertain. Deficiency of prothrombin, fibrinogen, platelets, factors V and VIII are the hallmark of the coagulation defects seen in cases of DIC (RodriguezErdman, 1965). These deficiencies in the clotting factors have been repeatedly shown in recent studies with purpura fulminans (Little, 1959; Glass, 1962; Bauhasin, 1964; Allen, 1966; Antley and McMillan, 1967; Dudgeon et al., 1971). Our patient had prolongation of bleeding time, clotting time (more than $1 \mathrm{hr}$ ), prothrombin time ( $\left.2 \frac{1}{2} \mathrm{~min}\right)$ and partial thromboplastin time $(6 \mathrm{~min})$ and a low platelet count $\left.50,000 / \mathrm{mm}^{3}\right)$ with a deficiency of fibrinogen $(20 \mathrm{mg} /$ $100 \mathrm{ml}$ ) were found. Although facilities for factor $\mathrm{V}$ and VIII assays were not available, the pattern of tests is regarded adequate for the evaluation of DIC (Antley and McMillan, 1967, Dudgeon et al., 1971).

Heparin is regarded as the therapeutic agent of choice in the management of purpura fulminans (Rodriguez-Erdman, 1965; Antley and McMillan, 1967) and successful treatment has been reported by Little (1959) and others (Glass, 1962; Antley and McMillan, 1967; Hattersley, 1970; Dudgeon et al., 1971). We were able to correct the coagulation 


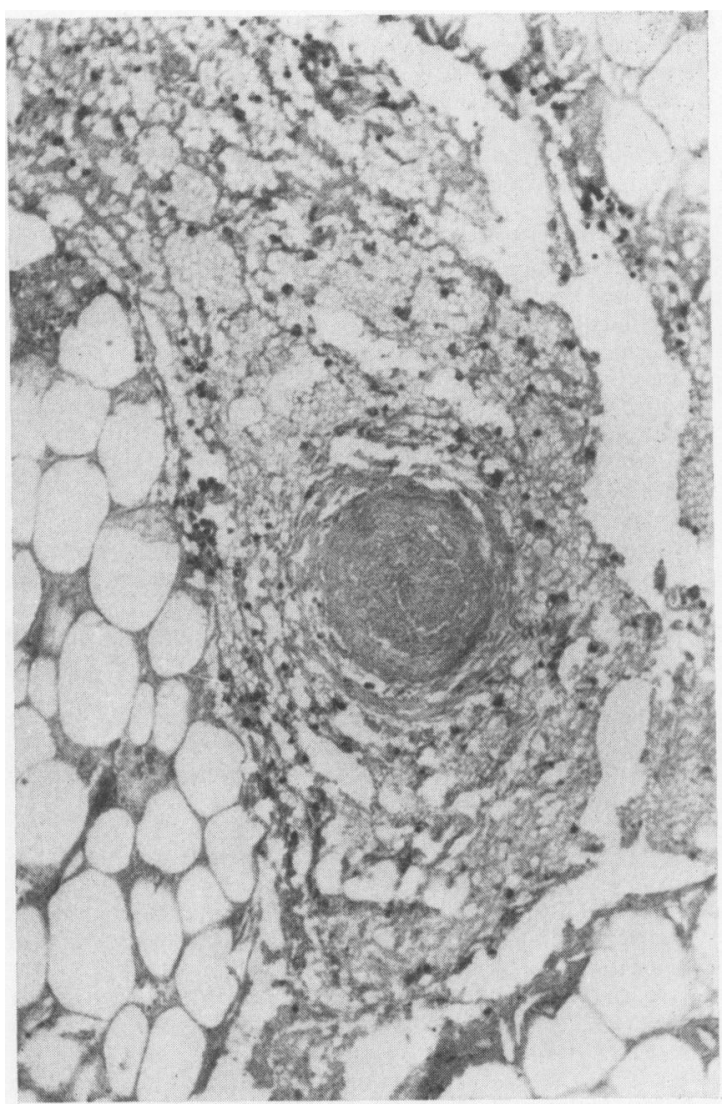

FIG. 3. Subcutaneous tissue from the affected area, showing thrombosis of a small blood vessel and cellular infiltration (haematoxylin and eosin $\times 252$ ).

abnormality in this patient by using continuous intravenous heparin drip within $72 \mathrm{hr}$. Although 8 days of heparin therapy has been regarded adequate by Frederiks and Huffstadt (1970), others reported that premature cessation is followed by haemorrhage and clinical deterioration (Antley and McMillan, 1967; Hattersley, 1970).

Corticosteroids have been used in the treatment of purpura fulminans, although they seem not to be indicated since they potentiate the Schwartzman phenomenon. In practice they are found to provide no clinical benefit to successful therapy (Crawford and Riddler, 1959; van Creveld et al., 1965).

Treatment with blood and fibrinogen has been advocated and although this mode of therapy is theoretically contraindicated since it supplies substrates for intravascular thrombosis, the results vary from further deterioration to complete recovery (van der Horst, 1962; Bauhasin, 1964).

Low molecular weight dextran has been used successfully and the beneficial effects are attributed to coating of vessel walls and the blood elements with prevention of sludging (Patterson et al., 1965; Smith, 1967).

Morse, Rowe and Hartigan (1966) treated two cases by using antifibrinolytic agent (Epsilon aminocaproic acid) and both recovered. Excessive plasma fibrinolytic activity is seen with DIC and in these cases it is regarded as secondary or defensive fibrinolysin with a protective role. Antifibrinolytic agents may be used in purpura fulminans, if it can be demonstrated that fibrinolytic activity is primary, since its use with secondary fibrinolysin consequent to DIC can be dangerous (Ratnoff, 1969; Seabaugh et al., 1971; Rodriguez-Erdman et al., 1971; McMillan, Weiss and Johnson, 1972).

Hyperbaric oxygen has been used with temporary improvement to save borderline necrotic tissues (Kuzemko and Loder, 1970; Dudgeon et al., 1971) and vitamins $\mathrm{K}, \mathrm{C}$ and rutin have also been employed (Chambers et al., 1952).

Anaemia is frequently associated with purpura fulminans and is usually attributed to external loss and extravasation. This patient had severe anaemia which was secondary to blood loss and a microangiopathic haemolytic process. The evidence for this type of anaemia was the grossly distorted and fragmented erythrocytes, normoblastaemia and a high reticulocyte count. In our review of the literature on purpura fulminans, its association with microangiopathic haemolytic anaemia is mentioned only twice (Hollingsworth and Mohler, 1968; Dudgeon et al., 1971). However, if carefully sought, it may be determined more frequently in view of the known association with conditions characterized by intravascular coagulation and fibrin deposition (Brain, Dacie and Hourihane, 1962).

This patient died in spite of the fact that the clotting abnormality was corrected and surgical debridement satisfactorily tolerated. Septic death in purpura fulminans has been reported and secondary infections of the skin lesions by both Gram-negative and Gram-positive organisms have also been observed (Hollingsworth and Mohler, 1968; Dudgeon et al., 1971). The nature of this enhanced susceptibility to infection remains unknown.

\section{Acknowledgments}

We thank Professor M. S. Chaudhry, Drs F. Y. Bashir, A. I. Dabbagh, A. M. Majeed and N. Al-Sakkal, and the staff of the Medical Research Laboratory, for their help in the preparation of this paper.

\section{References}

ALLEN, D.M. (1966) Heparin therapy of purpura fulminans. Pediatrics, 38, 211.

ANTley, R.M. \& McMillan, C.W. (1967) Sequential coagulation studies in purpura fulminans. New England Journal of Medicine, 276, 1287. 
Bauhasin, J.D. (1964) Purpura fulminans. Pediatrics, 34, 264.

Brain, M.C., Dacie, J.V. \& Hourihane, D.O'B. (1962) Microangiopathic anemia: The possible role of vascular lesions in pathogenesis. British Journal of Haematology, 8 , 358.

Brown, L.B. \& Nelson, A.R. (1967) Post infectious intravascular thrombosis with gangrene. Archives of Surgery, 94, 652.

Chambers, W.N., Holyoke, J.B. \& Wilson, R.F. (1952) New England Journal of Medicine, 247, 933.

Charkes, N.D. (1961) Purpuric chicken pox. Annals of Internal Medicine, 54, 745.

Cram, D.L. \& Soley, R.L. (1968). Purpura fulminans. British Journal of Dermatology, 80, 323.

CRaWford, S.E. \& RiddleR, J.G. (1959). American Journal of Diseases of Children, 97, 198.

Dudgeon, D.I., KellogG, D.R., Gilchrist, G.S. \& Woolley, M.M. (1971) Purpura fulminans. Archives of Surgery, 103, 351.

DuNN, H.G. (1951) Gangrenous purpura and its occurrence in meningococcaemic septicaemia. Archives of Disease in Childhood, 26, 184.

FishbeIN, R.H. (1969) Purpura fulminans: an analysis of the lesion and its treatment. Journal of Pediatric Surgery, 4, 320.

Frederiks, E. \& Huffstadt, A.J.C. (1970) Two cases of purpura fulminans. British Journal of Plastic Surgery, 23, 90.

GLASs, R.D. (1962) Purpura gangrenosa: report of a case with a discussion of the Schwartzman phenomenon. Medical Journal of Australia, 40, 300.

Hattersley, P.G. (1970) Purpura fulminans: complete recovery with intravenously administered heparin. American Journal of Diseases of Children, 120, 467.

Heal, F.C. \& Kent, G. (1953) Purpura fulminans with afibrinogenaemia. Canadian Medical Association Journal, 69, 367.

Huort, P.F., RAPAPORT, S.I. \& Jorgensen, L. (1964) Report of a case successfully treated with heparin and hydro- cortisone: review of 50 cases from the literature. Scandinavian Journal of Haematology 1, 169.

HOLlingsworTH, J.H. \& MoHLER, D.N. (1968) Microangiopathic hemolytic anemia caused by purpura fulminans. Annals of Internal Medicine, 68, 1310.

Kuzemko, J.A. \& Loder, R.E. (1970) Purpura fulminans treated with hyperbaric oxygen. British Medical Journal, 4, 157.

LitTLE, J.R. (1959) Purpura fulminans treated successfully with anticoagulation. Journal of the American Medical Association, 169, 104.

McMillan, C.W., Weiss, A.E. \& Johnson, A.M. (1972) Acquired coagulation disorders in children. Pediatric Clinics of North America, 19, 1029.

Morse, T.S., Rowe, M. \& Hartigan, M. (1966) Purpura fulminans. Archives of Surgery, 93, 268.

Patterson, J.H., Pierce, R.B., Amerson, J.R. \& Watkins, W.L. (1965) Dextran therapy of purpura fulminans. New England Journal of Medicine, 273, 734.

RATNOFF, O.D. (1969) Epsilon aminocaproic acid: A dangerous weapon. New England Journal of Medicine, 280 , 1124.

RoDriguez-ERdMANN, F. (1965) Bleeding due to increased intravascular blood coagulation. New England Journal of Medicine, 273, 1370.

Rodriguez-Erdmann, F., Button, L., Murray, J.E. \& MolONEY, W.C. (1971) Kasabach-Merritt syndrome: Coagulo-analytical observations. American Journal of Medical Sciences, 261, 9.

Seabaugh, D.R., Pappas, J., Seaman, A. \& Hodges, C.V. (1971) Disseminated intravascular coagulation and the urologist. Journal of Urology, 106, 267.

SMITH, H. (1967) Purpura fulminans complicating varicella recovery with low molecular dextran and steroids. Medica Journal of Australia, 2, 685.

van CReveld, S., van der Kolk, W.F.J., Mochtar, I.A. \& Muller, J. (1965) Purpura fulminans: A case with recovery. Clinical Pediatrics, 4, 23.

VAN DER HORST, R.H. (1962) Purpura fulminans in a newborn baby. Archives of Disease in Childhood, 37, 436. 